\title{
Synthesis and Performance Evaluation of Linear Polycarboxylate Dispersant of Glacial Acrylic Acid - Maleic Acid- Sodium Methallyl Disulfonate for Ceramics
}

\author{
Kiran Kumar Kommanapalli*;, Pierre Lyot*, Jhansi Rani Sunkara**, and Pierrick Checule* \\ *SNF SAS Dispersant Research Labs Division, Ceramic R\&D Lab, SNF Floerger, ZAC de Milieux 42163, Andrezieux Cedex, France \\ **Department of Chemistry, Andhra University, Visakhapatnam, Andhra Pradesh 530 003, India
}

(Received October 16, 2017; Revised February 20, 2018; Accepted February 22, 2018)

\begin{abstract}
Using aqueous solution free radical polymerization with glacial acrylic acid (GAA), maleic anhydride (MA) and sodium methallyl disulfonate (SMADS), a novel linear polycarboxylate dispersant was synthesized for ceramics. Dispersant linear structural characterization was done by FTIR, ${ }^{1} \mathrm{H}$ NMR, HPLC and GPC, and the ratio of monomers was determined using an orthogonal experiment. This research is focused on the effects of polymerization temperature, monomer mole ratios and dosage of initiator on ceramic slurry viscosity with linear polycarboxylate dispersant for ceramic dosage rate of $0.30 \%$ (based on dry slurry), all of which were investigated by single factor test. The best polymerization conditions for linear GAA-MA-SMADS are when $n(\mathrm{AA}): n(\mathrm{MA})$ : $n$ (SMADS) equals $3.0: 1.0: 0.5$, the molecular weight of the polymer is 4600 daltons, the initiator sodium persulfate accounts for $7 \%$ of the total mass of polymerized monomers, the polymerization temperature is $90^{\circ} \mathrm{C}$ and the reaction time is $2 \mathrm{~h}$. The ceramic body slurry viscosity drops from $820 \mathrm{mPa} \cdot \mathrm{s}$ to $46 \mathrm{mPa} \cdot \mathrm{s}$ when the concentration of the polycarboxylate dispersant is $0.30 \%$.
\end{abstract}

Key words : Novel linear polycarboxylate dispersant GAA-MA-SMADS, Ceramic dispersant, Polymerization, Ceramic slurry flow time, Slurry viscosities

\section{Introduction}

W ater reducing aids have been key additives in cement slurries, ceramics and concrete mixtures for a long time. ${ }^{1)}$ Ceramic admixtures use dispersants to reduce viscosity of slurry and hence operate at low moisture levels in glazes and ceramic bodies; they also improve the efficiency of pumps and other transfer equipment. ${ }^{2}$ This reduces energy consumption for the manufacturing of ceramic wares and also improves the grinding efficiency of ball mills. Many western countries that are leading world ceramic producers, like Germany, France and Italy, have effected important changes in this process. ${ }^{3)}$ Dispersant usage has also attracted a lot of ideas for continual process improvement. Starting from inorganic dispersants, this application has seen a promising upward drift in efficiency by using the latest organic dispersants ${ }^{4)}$ with macromolecular polymeric chains put together to achieve required process parameters and hence improved production quality. ${ }^{5}$ )

The journey of the dispersant is in two stages: the initial stage is the slow addition of liquid glass or sodium silicate, which is an inorganic dispersant.) After a lot of R\&D, new polymer technology has taken over and molecular chains of polycarboxylates have come into the picture. The improve-

${ }^{\dagger}$ Corresponding author : Kiran Kumar Kommanapalli

E-mail : kommanapalli.k@snf-india.com

Tel : +33-477368504 Fax : +91-8978889718 ments seen using organic dispersants have attracted lot of attention due to the compatibility of these materials with the process and their nonpolluting nature, as well as the strength of the final product and the better output of ceramic ware. ${ }^{7)}$

Even today, it has been observed that, with particular recipes of admixtures, the viscosity can rise above $130 \mathrm{mPa} \cdot \mathrm{s}^{8)}$ proving the need for much stronger organic dispersants. ${ }^{9)}$ In this view, the existing technology using glacial acrylic acid based dispersants, ${ }^{10,11)}$ maleic homo-polymers, ${ }^{12)}$ maleic acid and acrylic acid ${ }^{13,14)}$ based dispersants (copolymer of maleic and sodiumacrylate), sulfonic acid and acrylic acid ${ }^{15,16)}$ based dispersants (copolymer of sodiumacrylate and sulfonic acid), maleic anhydride and acrylic acid and methoxypolyethyleneglycol based products, ${ }^{17)}$ maleic anhydride and sodium allylsulfonate and methoxypolyethyleneglycol based products, ${ }^{18)}$ acrylic acid and sodium allylsulfonate, ${ }^{19)}$ acrylic and sodium methallyl sulfonates, ${ }^{20,21)}$ maleic acid and acrylic acid and sodium methallyl sulfonates based linear dispersants, ${ }^{9)}$ still need improved versions. This is the origin point of my work in this area.

A process of aqueous solution free radical polymerization is followed for the admixture of high silica and high alumina. Using GAA, MA and SMADS as the main synthetic materials, a novel group of linear GAA-MA-SMADS dispersants of polycarboxylate ceramics with reactive groups such as hydroxyl, carboxyl and sulfonic acids attached to their molecular structures can be formed; ${ }^{9)}$ these attachments 
will also be firmly absorbed onto the particle surfaces of ceramic bodies, in a laminate structure. By using orthogonal experiments, the ratio of monomers will be determined. The effects of each monomer and set of process conditions on the performance of linear GAA-MA-SMADS dispersants of ceramic polycarboxylate will be determined by single factor experiment.

\section{Experimental Procedure}

\subsection{Materials}

Sodium methallyl disulfonate- SMADS (SNF Inc), glacial acrylic acid (PT.NIPPON SHOKUBAI INDONESIA), maleic anhydride (Taiwan Prosperity Chemical Corporation), sodium persulfate- $\mathrm{Na}_{2} \mathrm{~S}_{2} \mathrm{O}_{8}$ (A.M.P.E.R.E. Industries S.A.S Lyon. Ltd France), water (Millipore water- HPLC quality), FlospersePE-35, ATBS-modified acrylic acid super plasticizer (industrial grade from SNF Floerger), ceramic composite slurries such as quartz/potash feldspar/kaolin clay (CLAYRIS CERAMIC) and the ceramic body composition are shown in Table 1, below.

\subsection{Synthesis of AA-MA-SMADS Polymer}

The GAA-MA-SMADS polymer was synthesized through

Table 1. Chemical Composition of Ceramic Body

\begin{tabular}{cc}
\hline Name of compound & wt.\% \\
\hline $\mathrm{SiO}_{2}$ & 73.82 \\
$\mathrm{Al}_{2} \mathrm{O}_{3}$ & 17.9 \\
$\mathrm{Fe}_{2} \mathrm{O}_{3}$ & 0.45 \\
$\mathrm{TiO}_{2}$ & 0.42 \\
$\mathrm{CaO}$ & 0.58 \\
$\mathrm{MgO}$ & 0.25 \\
$\mathrm{Na}_{2} \mathrm{O}$ & 0.37 \\
$\mathrm{~K}_{2} \mathrm{O}$ & 0.5 \\
$\mathrm{LOI}$ & 5.68 \\
$\mathrm{ZrO}$ & 0 \\
$\mathrm{BaO}$ & 0 \\
$\mathrm{ZnO}$ & 0 \\
\hline
\end{tabular}

aqueous solution free radical polymerization using sodium persulfate as an initiator Fig. 1. $60.4 \mathrm{~g}$ of maleic anhydride was added slowly to $345.2 \mathrm{~g}$ of DI water and $98.5 \mathrm{~g}$ of sodium hydroxide solution, heated to $55^{\circ} \mathrm{C}$ and dissolved; then, $83.1 \mathrm{~g}$ of SMADS was added to the above solution. Later, the total solution was transferred into a five neck 1.0 $\mathrm{kg}$ glass reactor and, after the solution was heated to $90^{\circ} \mathrm{C}$, $155.34 \mathrm{~g}$ of glacial acrylic acid and 7\% (wt) sodium persulfate (NaPS) aqueous solution were added dropwise to the reaction mixture; the total reaction time was $90 \mathrm{~min}$ and, after completion of the reaction, the material was aged at the same temperature for 30 minutes; then, after cooling to $60^{\circ} \mathrm{C}$, the $\mathrm{pH}$ value of the polymer was adjusted to 7.0 with $146 \mathrm{~g}$ of sodium hydroxide solution. . $^{911,13,15,19,24)}$

\subsection{Preparation of slurry}

Ceramic slurry recipe prepared using the available clays in compositions mentioned in Table 1 and $300 \mathrm{~g}$ of dry blanks were used and mixed thoroughly; materials had to be screened through 4 sieves and must be able to pass through a 250 Tyler mesh sieve. To obtain this fineness, the recipe was milled in a pot mill and, once it passes through the sieves, residue should be $<1 \%$; the green body slurry can be obtained naturally after iron removal. ${ }^{9,22)}$

\subsubsection{Characterization}

Fourier transform infrared (FT-IR) spectra, recorded on an FT-IR Spectrum-100 (Perkin Elmer, USA) in transmission mode, were in the $400-4000 \mathrm{~cm}^{-1}$ range, with $4 \mathrm{~cm}^{-1}$ resolution and an average of 16 scans.

${ }^{1} \mathrm{HNMR}$ spectra was recorded on a spectrometer (NMR AVANCE III HD $400 \mathrm{MH}_{\mathrm{Z}}$ ) with 24 sample cases (auto sampler) and BBO BB/1H $10 \mathrm{~mm}$ probe.

The molecular weight of the polymer spectra was recorded on an Agilent 1260 Infinity GPC/SEC system with Eluent$\mathrm{KH}_{2} \mathrm{PO}_{4}$; flow rate was $0.4 \mathrm{ml} / \mathrm{min}$ and injection volume was $100 \mu \mathrm{l}$.

Residual monomer content was determined via polymer chromatogram, recorded on an HPLC (Waters - alliance e2695-USA) with UV detector-2489.

A Gabbrielli ford type flow cup with an orifice of $4 \mathrm{~mm}$ (Gabbrielli - Italy B4 cup) was adopted to determine the rel-<smiles>C=C(C[18O][Na])C[13C](=O)[O-]</smiles>

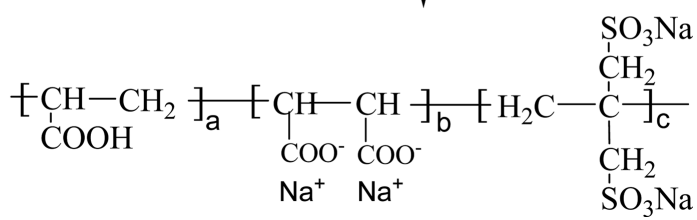

Fig. 1. Synthesis of GAA-MA-SMADS linear polymer through aqueous free radical polymerization. 
ative-mass ratio of the absolutely dry slurry; dispersing agents and the flow time of slurry system (t) are denoted by the efflux time of the Gabbrielli- 4 cup.

The viscosity of the ceramic slurry was measured using a digital viscometer (Brookfield-DV2TLV); the dispersing effect of our GAA-MA-SMADS based dispersant is found to be 5 times the average value of the measured viscosity.

The MOR (Modulus of rupture) of the dry ceramic green bodies was determined by a Flexi150 (Gabbrielli - Italy) digital ceramics anti bending instrument.

\section{Results and Discussion}

\subsection{Structural characterization of polymer}

The novel GAA-MA-SMADS polycarboxylate linear polymers were verified from their FTIR, H-NMR spectra and GPC HPLC chromatogram. The optimized synthesis process conditions were determined through orthogonal experiment.

\subsection{FT-IR}

FT-IR measurement was conducted to verify the GAAMA-SMADS polymer structure. Stretching and vibration of the characteristic absorption peak of carboxyl and the few hydroxyls on water molecules appeared at the wave number $3343.56 \mathrm{~cm}^{-1}$. The absorption characteristic peak of the symmetric vibration of carboxyl carbonyl appears at wave number of $1554 \mathrm{~cm}^{-1}$; the corresponding characteristic absorption peak of symmetric stretching and vibration appears at $1401.88 \mathrm{~cm}^{-1}$; the characteristic peak of symmetric bending vibration of methylene appears at $1450 \mathrm{~cm}^{-1}$, near the wave number of $1041.160 \mathrm{~cm}^{-1}$; the sulfonyl symmetric stretching and vibration peak emerges with its corresponding absorption peak of asymmetric stretching and vibration at the wave number of $1180.24 \mathrm{~cm}^{-1}$. Also, from Fig. 2, we can see that alkene has been totally polymerized as an alkene double bond because no stretching and vibration peak appears near the wave number of $1640 \mathrm{~cm}^{-1}$. Therefore, groups such as hydroxyls, carboxyls and sulfonyls are contained and serve the function of highly dispersing in the molecular structure of polycarboxylate ceramic, which basically corresponds to the anticipated design.

\section{3. ${ }^{1} \mathrm{H}-\mathrm{NMR}$}

${ }^{1} \mathrm{H}-\mathrm{NMR}$ spectroscopy is also a powerful spectroscopic method that can be used to perform structural and functional characterization of the GAA-MA-SMADS synthesized polymer Fig. 3. ${ }^{1} \mathrm{H}$ NMR peaks of $2.6-2.3 \mathrm{ppm}$ are attributed to $-\mathrm{CH}$ (MA), $\mathrm{CH}_{2}$ in alpha of $\mathrm{SO}_{3} \mathrm{H}$ is often found at around $2.8-3.2 \mathrm{ppm}$ (SMADS), while $-\mathrm{CH}_{2}$ from the polymer back bone has a range of $1.8-1.0 \mathrm{ppm}$.

\section{4. $G P C$}

GPC is used to determine the molecular weight and polydispersity of synthesized GAA-MA-SMADS terpolymer

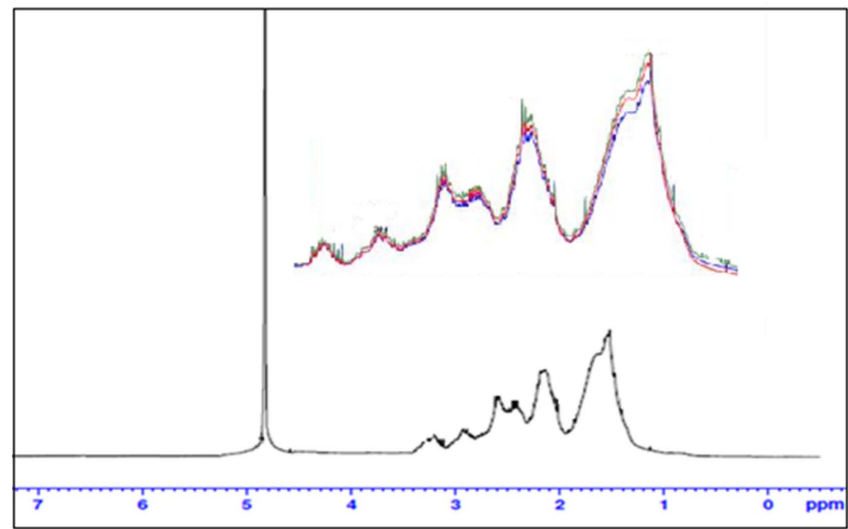

Fig. 3. ${ }^{1} \mathrm{H}-\mathrm{NMR}$ spectrum of GAA-MA-SMADS polymer.

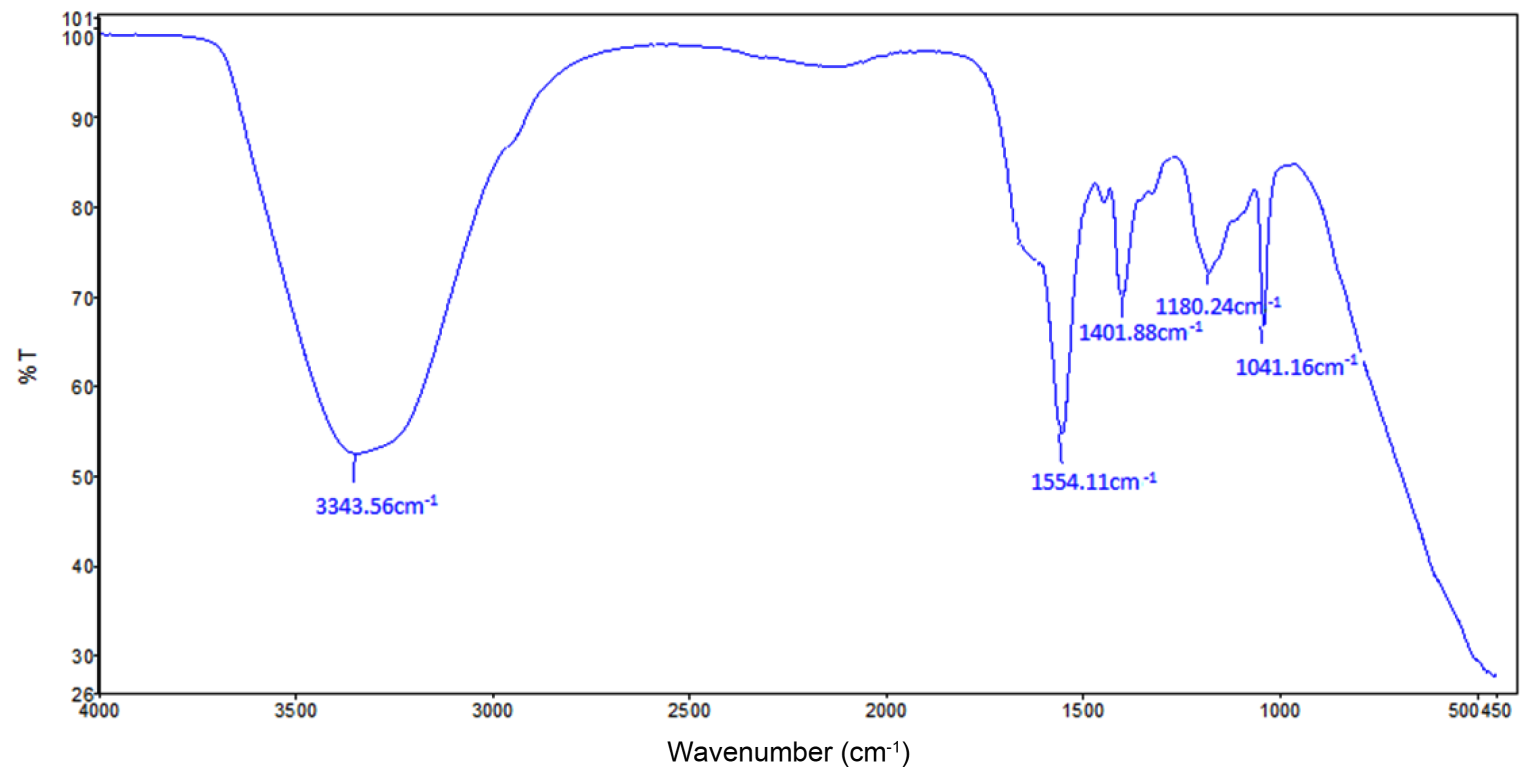

Fig. 2. FT-IR spectrum of GAA-MA-SMADS polymer. 


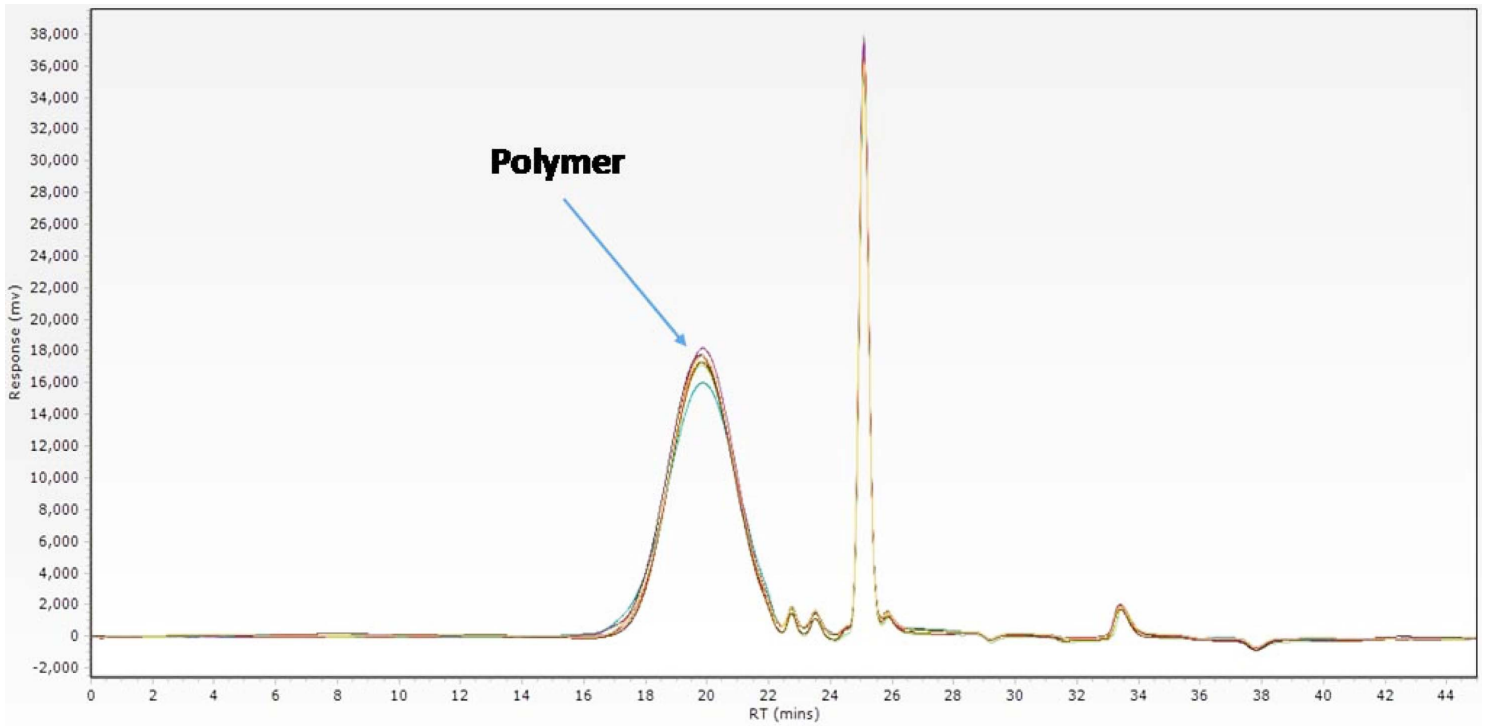

Fig. 4. GPC -Molecular weight in chromate grams of GAA-MA-SMADS polymer.

Table 2. Molecular Weight and Polydispersity of GAA-MASMADS Terpolymer

\begin{tabular}{cc}
\hline $\begin{array}{c}\text { Molecular weight }(\mathrm{Mw}) \\
\mathrm{g} / \mathrm{mol}\end{array}$ & $\begin{array}{c}\text { Polydispersity index } \\
(\mathrm{PDI})\end{array}$ \\
\hline 4600 & 1.2 \\
\hline
\end{tabular}

samples (Agilent 1260 Infinity GPC/SEC equipment). Molecular weight of synthesized novel GAA-MA-SMADS polymer was $4600 \mathrm{~g} / \mathrm{mol}$ daltons and polydispersity was 1.2 (PDI) Table 2; polymer has shown excellent slurry viscosities properties Fig. 4.

\subsection{HPLC}

A high performance liquid chromatogram is a powerful tool that can be used to determine the residual monomer presence in the final polymer sample. A UV-visible detector (Waters -USA Detector 2489) was used, with a wavelength of $205 \mathrm{~nm}$, column-Acclaim OA, m250 × $4.0 \mathrm{~mm}, 5 \mu$, injection volume of $20 \mu \mathrm{l}$, analysis time of 20 minutes, flow time of $0.7 \mathrm{ml} / \mathrm{min}$ and work pressure of $1800 \mathrm{psi}$. The chromatogram indicated residual monomer levels of maleic acid of 2 ppm at 6.92 minutes, SMADS of $4 \mathrm{ppm}$ at 14.66 minutes and glacial acrylic acid of $10.5 \mathrm{ppm}$ at 16 minutes Fig. 5 .

\subsection{Determination of optimized synthesis process parameters}

The orthogonal experiment method is adopted to determine the optimized parameters for synthesis of GAA-MASMADS linear polycarboxylate dispersant. The main factors influencing the water reduction effect of the polycarboxylate ceramic dispersant are the polymerization temperature, the weight of initiator $w(\mathrm{NaPS})$, the monomer ratios and the polymerization time. ${ }^{9)}$ Under these circumstances, the polymerization time of $2 \mathrm{~h}$ and feeding mode are determined; the $\mathrm{L}_{16} 4^{5}$ test has been carried out; the 5 important

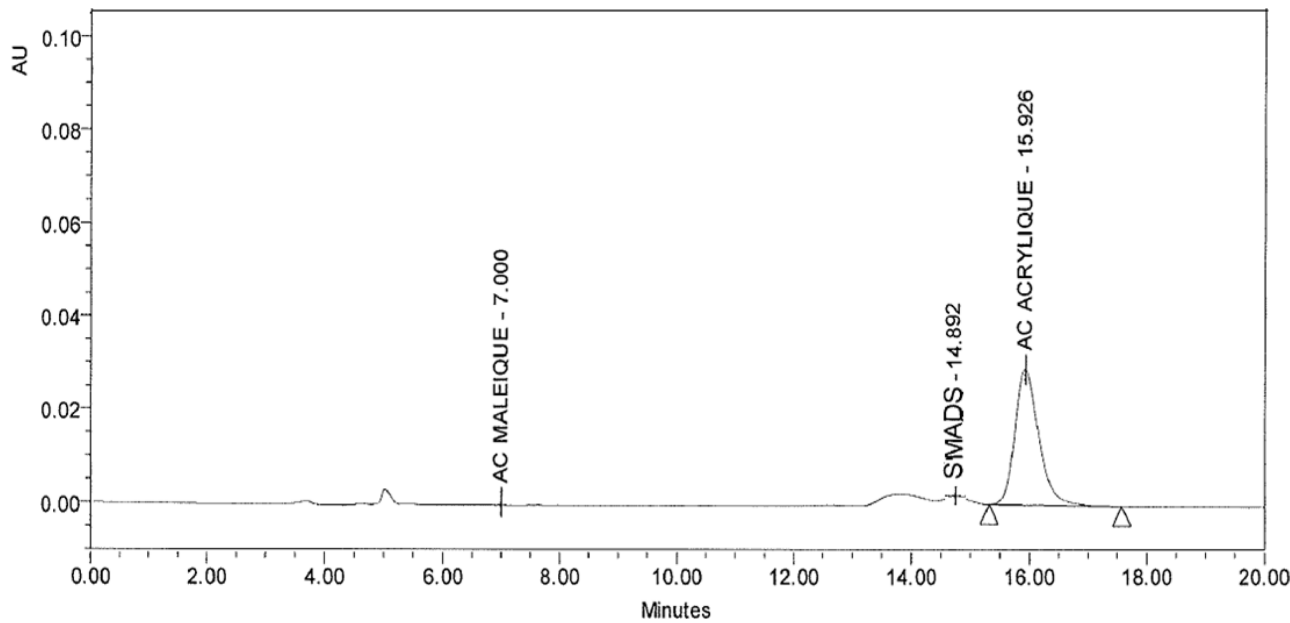

Fig. 5. HPLC -chromatogram of GAA-MA-SMADS polymer. 
Table 3. Levels and Factors $\left(L^{5}\right)$

\begin{tabular}{cccccc}
\hline Level & Polymerization & Catalyst & $\mathrm{n}(\mathrm{MA}) / \mathrm{mol}$ & $\mathrm{n}(\mathrm{GAA}) / \mathrm{mol}$ & $\mathrm{n}(\mathrm{SMADS}) / \mathrm{mol}$ \\
\hline 1 & 85 & 6 & 1 & 2.5 & 0.25 \\
2 & 90 & 7 & 1.5 & 3 & 0.5 \\
3 & 95 & 8 & 2 & 3.5 & 0.75 \\
4 & 100 & 9 & 2.5 & 4 & 1 \\
\hline
\end{tabular}

Table 4. Orthogonal Experiment Analysis Results $\left(\mathrm{L}_{16} 4^{5}\right)$

\begin{tabular}{|c|c|c|c|c|c|c|}
\hline Level & Polymerization/C & Catalyst & $\mathrm{n}(\mathrm{MA}) / \mathrm{mol}$ & $\mathrm{n}(\mathrm{GAA}) / \mathrm{mol}$ & $\mathrm{n}(\mathrm{SMADS}) / \mathrm{mol}$ & Flow time/s \\
\hline 1 & 85 & 6 & 1 & 2.5 & 0.25 & 34.01 \\
\hline 2 & 85 & 7 & 1.5 & 3 & 0.5 & 17.04 \\
\hline 3 & 85 & 8 & 2 & 3.5 & 0.75 & 41 \\
\hline 4 & 85 & 9 & 2.5 & 4 & 1 & 48.24 \\
\hline 5 & 90 & 6 & 1.5 & 3.5 & 1 & 37.12 \\
\hline 6 & 90 & 7 & 1 & 4 & 0.75 & 38.66 \\
\hline 7 & 90 & 8 & 2.5 & 2.5 & 0.5 & 37 \\
\hline 8 & 90 & 9 & 2 & 3 & 0.25 & 22.02 \\
\hline 9 & 95 & 6 & 2 & 4 & 0.5 & 37.1 \\
\hline 10 & 95 & 7 & 2.5 & 3.5 & 0.25 & 44.24 \\
\hline 11 & 95 & 8 & 1 & 3 & 1 & 24.84 \\
\hline 12 & 95 & 9 & 1.5 & 2.5 & 0.75 & 38 \\
\hline 13 & 100 & 6 & 2.5 & 3 & 0.75 & 32.87 \\
\hline 14 & 100 & 7 & 2 & 2.5 & 1 & 38 \\
\hline 15 & 100 & 8 & 1.5 & 4 & 0.25 & 46.22 \\
\hline 16 & 100 & 9 & 1 & 3.5 & 0.5 & 32 \\
\hline Average Value 1 & 35.07 & 35.28 & 32.38 & 36.75 & 36.62 & - \\
\hline Average Value 2 & 33.7 & 34.49 & 34.6 & 24.19 & 30.79 & - \\
\hline Average Value 3 & 36.05 & 37.27 & 38.59 & 38.59 & 37.63 & - \\
\hline Average Value 4 & 37.27 & 35.07 & 40.59 & 42.56 & 37.05 & - \\
\hline Range & 3.57 & 2.78 & 8.21 & 18.37 & 6.84 & \\
\hline
\end{tabular}

factors are the polymerization temperature, the weight of the initiator, the SMADS mole fraction $n$ (SMADS), the GAA mole fraction $n(\mathrm{GAA})$, the MA mole fraction $n(\mathrm{MA})$ and the polymerization time. Four levels are selected for each factor and details are shown in Table 3 . The flow time of the slurry system serves as the parameter for evaluation; therein, the admixture quantity ratio of the dispersants of the slurry system is $0.30 \%$ (relative-mass ratio of absolutely dry slurry); the results are shown in Table 3.

From orthogonal experiment results (Table 3), impacts of 5 factors on the slurry system can be arranged in order as the impact grows gradually, as follows: $n(\mathrm{GAA})>n(\mathrm{MA})>$ $n($ SMADS $)>$ polymerization temperature $>w$ (catalyst). The average values indicate (Table 3 ) that the optimized synthesized conditions of linear GAA-MA-SMADS polycarboxylate molecule are under $2 \mathrm{~h}$ polymerization time and $90^{\circ} \mathrm{C}$ temperature, as well as $w$ (catalyst) $=7 \%$ and $n(\mathrm{GAA}): n(\mathrm{MA})$ : $n(\operatorname{SMADS})=3.0: 1.0: 0.5$.

\subsection{Single factor experiment}

\subsubsection{Impact of $n(\mathrm{GAA})$}

This section describes the variation in ceramic body slurry viscosity with mole fraction of glacial acrylic acid (GAA) when other conditions stay unchanged, that is, $n(\mathrm{MA})$ : $n$ (SMADS) equal to $1: 0.5$, catalyst $7 \%$ of total mass of the monomer, polymerization temperature $90^{\circ} \mathrm{C}$ and reaction time $2 \mathrm{~h}$.

When $n(\mathrm{GAA})<3.0$, as the $n(\mathrm{GAA})$ decreases, the slurry flow times are prolonged drastically; when $n(\mathrm{GAA})>3.0$, as $n(\mathrm{GAA})$ increases, the slurry flow times gradually slow down. Thus, the best value for $\mathrm{n}(\mathrm{GAA})$ is 3.0 Fig. 6 .

This is because, as $n(\mathrm{GAA})=3.0$ increases, the opportunities for monomers to trigger the polymerization will increase, which may likely form long-molecule chains and prolong the flow time of the slurry of the ceramic body; when $n$ (GAA) exceeds 3.5, the conversion efficiency will be highly enhanced, which gives rise to an increase of $n(-\mathrm{COOH})$ on the main chain; thereby, the slurry system tends to be sta- 


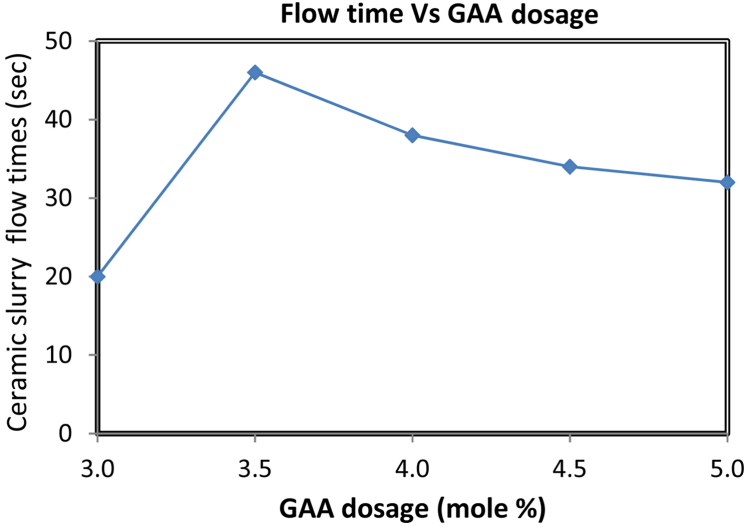

Fig. 6. Change tendency of ceramic slurry viscosity as it varies with GAA mole fractions.

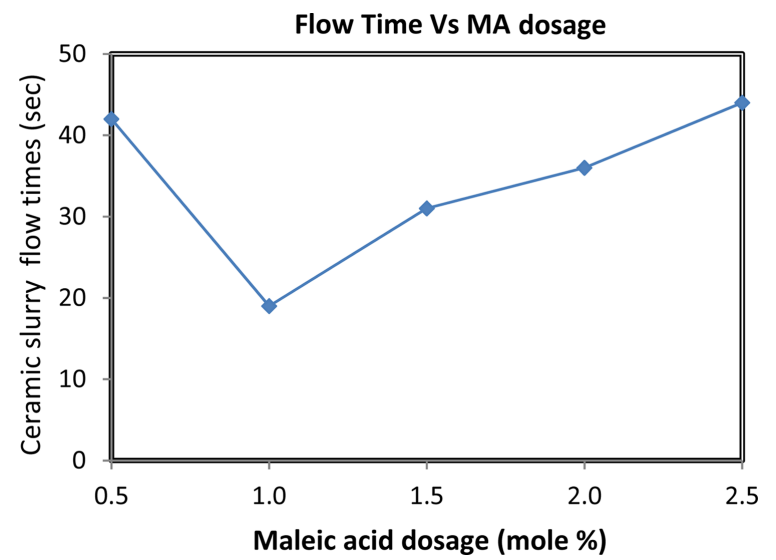

Fig. 7. Change tendency of ceramic slurry viscosity as it varies with MA mole fractions.

ble and the flow time appears to gradually shorten; therefore, $n(\mathrm{GAA})=3.0$ is the most suitable condition.

\subsubsection{Impact of $n(\mathrm{MA})$}

When other conditions stay unchanged, that is, $n(\mathrm{GAA})$ : $n$ (SMADS) equals $3: 0.5$, the catalyst is $7 \%$ of the total mass of the monomer, the polymerization temperature is $90^{\circ} \mathrm{C}$ and the reaction time is $2 \mathrm{~h}$. The polycarboxylate dosage is $0.30 \%$ (absolute dry slurry based); Fig. 6 clearly shows the ceramic slurry viscosity changes with $n(\mathrm{MA})$ ratios.

When $n$ (MA) equals 1.0 (Fig. 6), the slurry viscosity reaches its lowest level in 19 seconds, with increasing values of $n(\mathrm{MA})$, till it reaches a value of 1 . It is observed that flow time of slurry also drops with $n$ (MA). If $n(\mathrm{MA})>1$ the polycarboxylate (-COOH) molecules will increase as $n(\mathrm{MA})$ increases and this greatly improves the function of absorption of the polycarboxylate molecules onto the surfaces of the clay particles, thus reducing the flocculation capacity of clay particles via the addition of polycarboxylate. This is purely due to the phenomenal increase of electric potential via better absorption of polycarboxylate by surface clay particles. Here, $n(\mathrm{MA})=1.0$ is the most suitable condition.

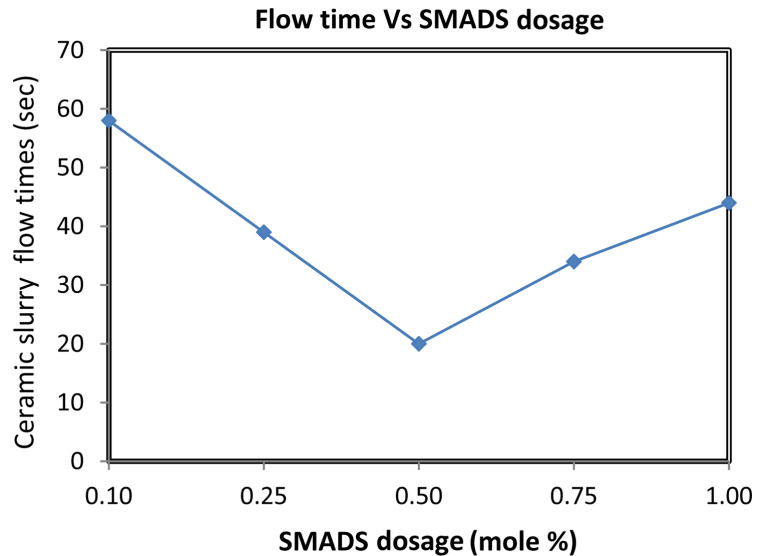

Fig. 8. Change tendency of ceramic slurry viscosity as it varies with SMADS mole fractions.

\subsubsection{Impact of $n$ (SMADS)}

When other conditions stay unchanged, that is, $n$ (GAA): $n(\mathrm{MA})$ is $3: 1$, the catalyst is $7 \%$ of the total mass of the monomer, the polymerization temperature is $90^{\circ} \mathrm{C}$ and the reaction time $2 \mathrm{~h}$, the polycarboxylate dosage is $0.30 \%$ (absolute dry slurry based), Fig. 7 clearly shows that the ceramic slurry viscosities change with the $n$ (SMADS) ratios.

When $n$ (SMADS) equals 0.5 (Fig. 7) the slurry viscosity reaches its lowest level, with increasing values of $n$ (SMADS), till it reaches the value 0.5 ; it is observed that the flow time of the slurry also drops with $n$ (SMADS). Using a small amount of SMADS can provide a small content of sulfonic acid functional groups $\left(-\mathrm{SO}_{3} \mathrm{H}\right)$ in the polycarboxylate dispersant. The electrostatic repulsion provided can be seen to be insufficient to extend the flow time of the slurry of the ceramic body of polycarboxylate ceramic dispersant of GAAMA-SMADS. However, it is not appropriate to use too large a quantity of SMADS, as the number of carboxyl functional groups drops, leading to the absorption function being too greatly lowered in proportion, which gives rise to an obvious decline in absorption quantity of slurry particles on the surface of the ceramic body onto the dispersant molecules of linear GAA-MA-SMADS polycarboxylate ceramics; as a result, the $\zeta$-electric potential on the particle surface of the ceramic body will decrease, the electrostatic repulsion will be weakened, and the flow time for the ceramic body slurry will be prolonged. Therefore, $n(\mathrm{SMADS})=0.5$ is the most suitable condition.

\subsubsection{Impact of $w$ (Catalyst)}

Under the condition of $90^{\circ} \mathrm{C}$ polymerization temperature and $2 \mathrm{~h}$ polymerization time, the acquired proportion of $n(\mathrm{GAA}): n(\mathrm{MA}): n(\mathrm{SMADS})=3.0: 1.0: 0.5$ and there is $0.3 \%$ admixture quantity ratio of dispersant. We can see in Fig. 8 the change tendency of the slurry viscosity as it varies with $w$ (Catalyst).

When $w$ (catalyst) $<7.0$, as catalyst quantity increases, the flow time of the slurry system is gradually shortened; when $w$ (catalyst) $>7 \%$, as the catalyst quantity increases, the 


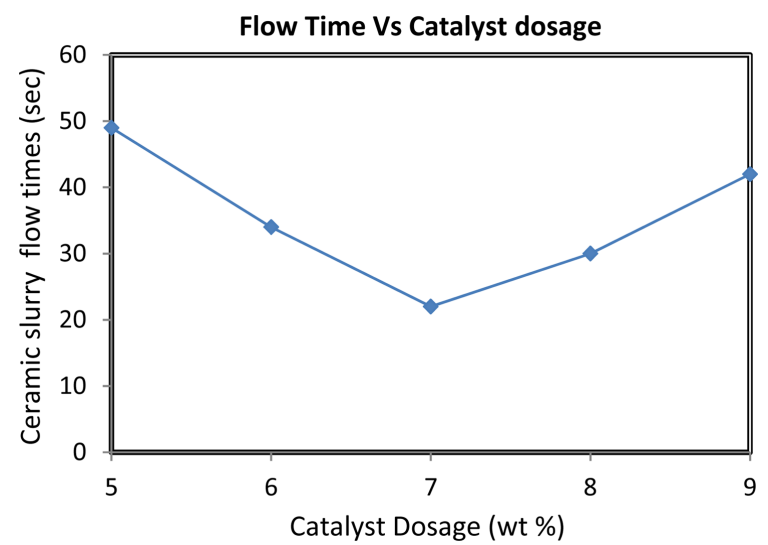

Fig. 9. Change tendency of ceramic slurry viscosity as it varies with $w$ (Catalyst) fractions.

flow time of the slurry system continuously increases. So, $w$ (catalyst $)=7 \%$ serves as the inflection point. If excess catalyst is added, the polymerization kinetics will be too fast and the relative molecular weight dispersant will be too low, resulting in slurry viscosity increase. If the amount of catalyst is reduced, the polymerization kinetics will be too low and this will lead to low molecular weight of the product, resulting in an increase of the flow time of the slurry system. Therefore, $w$ (catalyst) $=7 \%$ will be the optimal value.

\subsubsection{Impact of polymerization temperature}

Under the condition of $2 \mathrm{~h}$ polymerization time, the acquired proportion of $n(\mathrm{GAA}): n(\mathrm{MA}): n(\mathrm{SMADS})=1.0:$ $3.0: 0.5, w$ (catalyst $)=7 \%$ and there is a $0.30 \%$ admixture quantity ratio of dispersant (dry slurry based). Fig. 9 shows the change tendency of the slurry system as it varies with the change of the polymerization temperature Fig. 10.

If the polymerization temperature is lower than $90^{\circ} \mathrm{C}$, as the polymerization time increases, the flow time of the ceramic slurry system will drop rapidly; if the polymerization temperature is higher than $90^{\circ} \mathrm{C}$, as the polymerization time increases, the flow time of the ceramic slurry system will be slowly prolonged. The $90^{\circ} \mathrm{C}$ polymerization tempera-

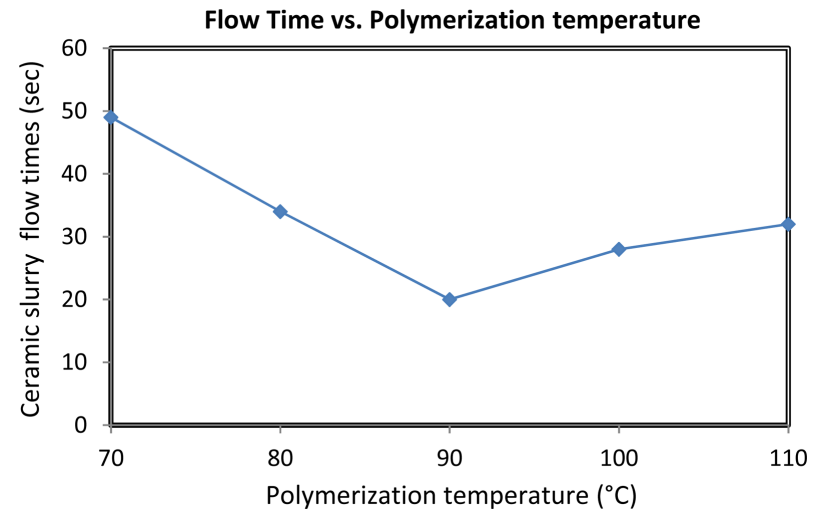

Fig. 10. Change tendency of ceramic slurry viscosity as it varies with polymerization temperature. ture serves as the inflection point. If the polymerization time is below $90^{\circ} \mathrm{C}$, as the polymerization temperature increases, the heating catalyst will decompose easily and generate a large quantity of free radicals in polymerization, which will accelerate the rate of reaction and affect the molecular weight of the polymers due to the termination effect of polymerization by free radicals. This enhances the free flow or fast flow of the ceramic slurry. Once the process temperature goes beyond $90^{\circ} \mathrm{C}$, the catalyst will decompose faster and this will increase the polymerization reaction. Due to the high temperature, glacial acrylic acid also starts cross linking, and hence reduces the flow time of the ceramic slurry. So, $90^{\circ} \mathrm{C}$ is the optimum temperature for polymerization.

\subsection{Ceramic Linear AA-MA-SMADS Polycarboxyl- ate Performance: comparison of different industrial dispersant grades}

Figure 11 shows the ATBS modified polyacrylic acid super plasticizers-comb structured, ${ }^{23,24)}$ Flosperse PE-35 commercial dispersants (linear structured) \& Linear GAA-MASMADS polycarboxylate's effect on flow time of ceramic slurry with constant dry solids and changing dosages.

Figure 11 shows the trends of viscosity of the ceramic slurry with increasing dosages of different dispersants, which include AMPS modified acrylic acid superplasticizer, Flosperse PE 35 and linear GAA-MA-SMADS terpolymer. All dispersants showed actions that followed a regular inverted parabolic curve, which means a reduction of viscosity initially, up to a point, and then an increase in viscosity with increasing dosages.

The ATBS-modified polyacrylic acid superplasticizer showed its lowest viscosity of $270 \mathrm{mPa} \cdot \mathrm{s}$ at $0.5 \%$ dosage; this value increased with further increases in dosage. Also, GAA-MA-SMADS and Flosperse PE-35 recorded their lowest viscosities at $46 \mathrm{mPa} \cdot \mathrm{s}$ and $70 \mathrm{mPa} \cdot \mathrm{s}$. Considering the effects of all dispersants, it is found that GAA-MA-SMADS gives good results in terms of low viscosity and flow time

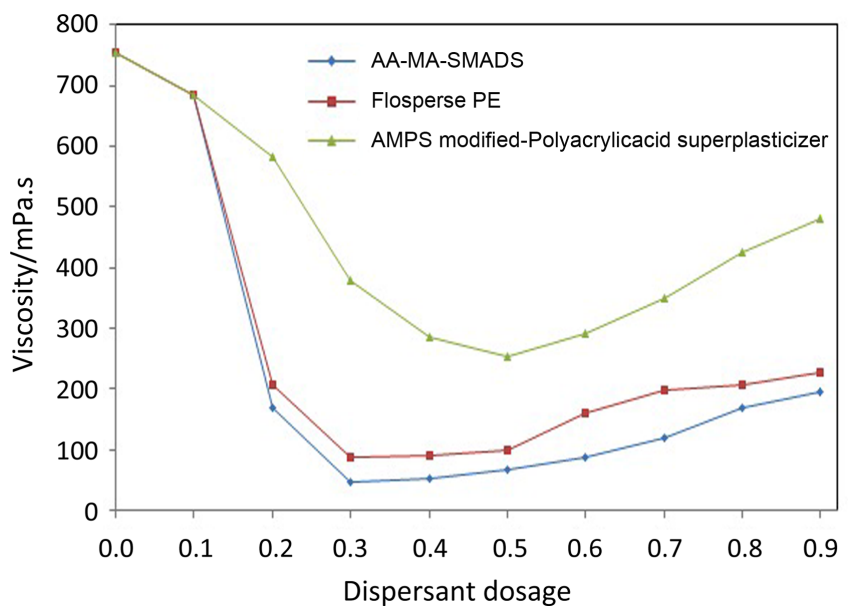

Fig. 11. Change tendency of ceramic slurry viscosity as it varies with different dispersants. 
with the same combination of clays.

The reason for this could be the strong steric layer formed around the solid particles, which are not easily disturbed and, hence, no flocculation effect can be observed in between the particles. Also, the anionic molecules of this type of polycarboxylate are found to absorb on clay particles easily, so that whenever these particles come closer the electrical double layers intercepts/overlaps with each other and hence keep the solids in good suspension as the reverse flocculation effect occurs, i.e., an efficient dispersion of solids is observed although. ${ }^{9,23,24)}$

\subsection{Linear Dispersant effect on MOR-Strength of dry green body (MOR-Modulus of rupture)}

Linear dispersants have been proven to be better in terms of MOR strength as their absorption capacity becomes higher, and in some cases they contain long linear chains that show probability of crosslinking with each other, as well as anti-aggregate forming capacity due to inter particular repulsion. Hence they maintain the suspension in an active state and yield better strength uniformly, all over the green body. In combined dispersants, the suspension property is relatively poor and chances of small aggregate formation are high. Due to this non-uniform distribution of particles in the green body, strength will be low compared to linear polycarboxylates.

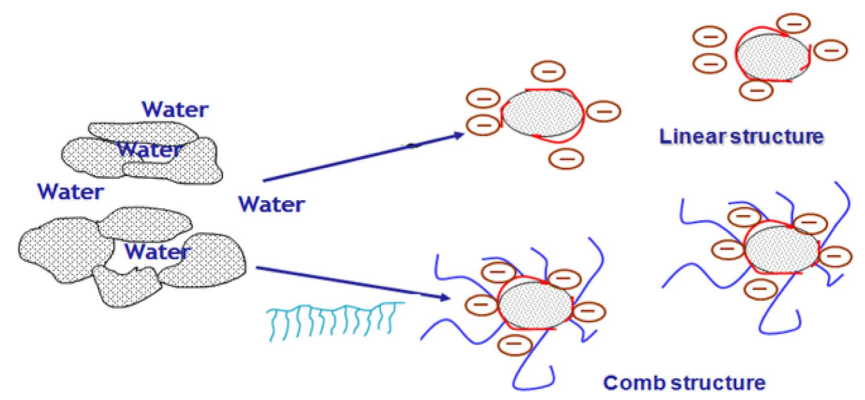

Fig. 12. Difference between comb and linear structured dispersant molecules.

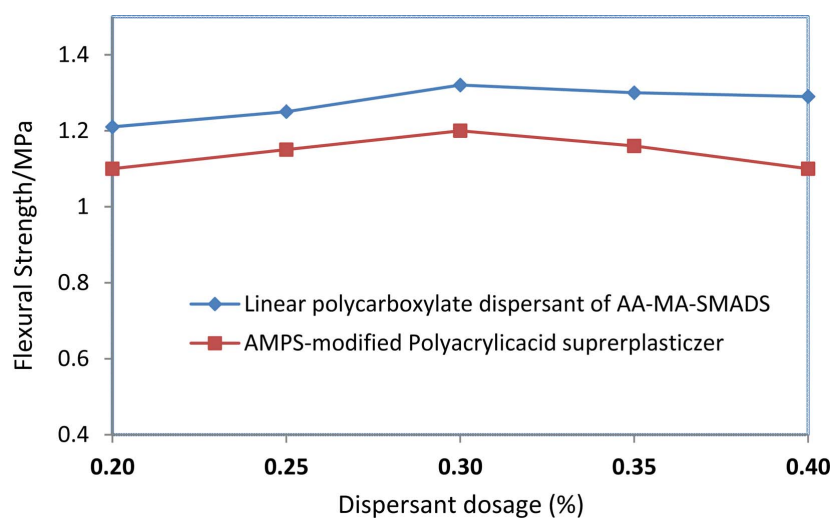

Fig. 13. Change tendency of dispersant dosage on flexural strength of ceramic body.

\section{Conclusions}

In this research, the novel linear polymer GAA-MASMADS was synthesized through aqueous solution free radical polymerization using sodium persulfate as an initiator. Characterization was performed through FTIR and NMR; molecular weight of the polymer was analyzed at the point where the polymer showed good performance; HPLC was used to measure the residual monomer levels in final product. The process parameters were set using the optimum values achieved through orthogonal experiment, i.e., $n(\mathrm{GAA}): n(\mathrm{MA}): n(\mathrm{SMADS})=3.0: 1.0: 0.5$ and $w(\mathrm{NaPS})=$ $7 \%$. The polymerization temperature and time are $90^{\circ} \mathrm{C}$ and $2 \mathrm{~h}$, respectively; the optimized admixture quantity ratio of linear dispersant is $0.30 \%$ (relative-mass ratio of absolute dry slurry); and, with such amounts of admixture, the dispersing effectiveness proved to be preferred; with viscosity of only $46 \mathrm{mPa} \cdot \mathrm{s}$, the anti-bending strength of the dry green body was high at $1.34 \mathrm{mPa} \cdot \mathrm{s}$.

\section{Acknowledgments}

The authors would like to thank the Research Director, SNF SPCM \& SNF INDIA, for his constant encouragement and permission to use the manuscript for publication. Dr. Cedrick Favero, Pierre Lyot and Pierrick Cheucle would like to thank the members of the Dispersants Scientist Group and Industrial Research and Development teams, in France and India, for this Research.

\section{REFERENCES}

1. H. Fei and X. Wei, "The Peptization and Effect Assessment of Water Treatment Surfactant on Ceramic Raw Material," Shandong Ceram., 22 [6] 594-98 (2012).

2. S.-F. Guo, Y.-X. Fang, Y.-H. Deng, and X.-Q. Qiu, "Study on the Performance and Compatibility of the LigninBased Dispersant for Ceramic Slurry," Fine Chem., 28 [6] 594-98 (2011).

3. S.-H. Zhang, M. Zhang, and J.-T. Jia, "Progress of Ceramic Water Reducing Agent,” Bull. Chin. Ceram. Soc., 32 [4] 677-82 (2013).

4. M. S. Eygi and G. Atesok, "An Investigation on Utilization of Polyelectrolytes as Dispersant for Kaolin Slurry and its Slip Casting Properties," Ceram. Int., 34 [8] 1903-8 (2008).

5. A. A. Zaman, R. Tsuchiya, and B. M. Moudgil, "Adsorption of a Low-Molecular Weight Polyacrylic Acid on Silica, Alumina, and Kaolin," J. Collid Interface Sci., 256 [1] 73-8 (2011).

6. L. Behal and D. Schelker, "Effects of Polyacrylate and Sodium silicate Dispersants on Plaster Mold Characteristics," pp. 23-29 in proceedings of the Ceramics Engineering Science, United states, 1996.

7. L. Xiaorui and W. Haihua, "Preparation and Relationship between the Structure and Properties of Novel Ceramic Dispersant," China Ceram., 12 [02] 542-48 (2005).

8. C. Bao-Fan, "Synthesis and Properties of an AMPS- 
Modified Polyacrylic Acid Superplasticizer," J. Wuhan Univ. Technol. (Materials Science Edition), 03 122-28 (2013).

9. B.-A. Chen, "Preparation and Properties of Polycarboxylate Dispersants of Linear MA-AA-MAS for Ceramics," Bull. Chin. Ceram. Soc., 2 [09] 2223-31 (2014).

10. B.-Y. Jiang, H.-G. Ji, B. Liao, H.-L. Liu, and P. Hao, "Preaparation and Performance of Sodium Polyacrylate for Ceramic Superplasticizer," Fine Chem., 28 [10] 1004-9 (2011).

11. J. H. Yang, X. Q. He, and H. Wang, "Synthesis of Low Molecular Weight Poly-Acrylic Acid Sodium and Application in Ceramics," Foshan Ceram., 2005 [04] 112-18 (2005).

12. L. Wang, F. Wang, B. Guo, Q. Ke, K. Zhao, and X. Yuan, "Research on Preparation, Structure and Properties of Copolymer Maleic Anhydride Superplasticizer," Mater. Rev., 22 [10] 33-6 (2010).

13. D. J. Gale and S. C. Spartanburge, US Patent 3,635,915 (January 18, 1972).

14. K. Cui, X.-L. Zou, and Y.-J. Lan, "Study on Synthesis of Maleic Anhydride-Acrylic Acid Copolymer," Fine Chem., 14 [02] 82-8 (2010).

15. Y.-S. Ye, H.-L. Huang, and K.-C. Hsu, "A Water-Soluble Acrylate/Sulfonate Copolymer. I. Its Synthesis and Dispersing Ability on Cement," J. Appl. Polym. Sci., 100 [3] 2490-96 (2006).

16. Q.-Q. Huang, B. Liao, B.-Y. Jiang, and B. Wang, "Preparation and Charcterization of AA-AMPS Copolymer Dispersant for Ceramic Powder," Fine Chem., 2013 [03] 339-
43 (2013).

17. B. Wang, W.-Q. Liu, H. Pang, Q.-F. Zeng, and R. Zhang, "Synthesis of High Performance Ceramics Superlasticizers and its Application," Guangzhou Chem., 2013 [03] 8894 (2013).

18. R. Wei, J. Zhou, and G. Xiao, "Synthesis and Performance of Polycarboxylate Based Superplasticizer by Free Radical Copolymerization in Aqueous Solution," J. Southeast Univ. 20 [6] 222-40 (2009).

19. L. Lei, Z. Guang-hua, and F. Xiao-long, "Preparation and performance of ultra Low Molecular weight AA/SAS Copolymer dispersant for Cramic Powder," Fine Chem., 28 [04] 82-94 (2014).

20. L. Dammann and K. Crestwood, US Patent 4,451,628 (May 29, 1984).

21. Y. Zhang, L. Meng, and L. Meng, "Research on Synthesis and Application of Linear Polycarboxylate Superplasticizer," Chinese Ceram., 46 [4] 65-8 (2010).

22. D. Santos, J. Manna, and M. Kramer, CN101550291B. (March 30, 2009).

23. E. Sakai, K. Yamada, and A. Ohta, "Molecular Structure and dispersion-adsorption mechanism of comb type superpalsticizers used in Japan,” J. Adv. Concr. Technol., 1 [1] 16-25 (2003).

24. C. Li, N. Feng, D. Wang, and Y. Hou, "Preparation and Characterization of Comb-like Polycarboxylic Water Reducer and it's Function Mechanism," J. Chinese Soc., 33 [1] 8792 (2005). 